State University organized a special session on Strict Topologies which included as participants Professors Steven F. Bellenot, R. A. Fontenot, William H. Graves, Denny Gulick, Dennis Sentilles, W. H. Summers, Donald C. Taylor, and Robert F. Wheeler. Professors Robert Gilmer and J. L. Mott of Florida State University organized a special session on Commutative Rings in which the participants were Professors D. D. Anderson, J. T. Arnold, Hyman Bass, Paul M. Eakin, Eloise Hamann, Stephen McAdam, T.-T. Moh, Judith D. Sally, Arvinash Sathaye, and David Wright. A third special session was organized by Professor Mary-Elizabeth Hamstrom of the University of Illinois. The topic of Professor Hamstrom's session was Geometric Topology and the participants included Professors Frederick D. Ancel, Joan S. Birman, Robert F. Craggs, Robert J. Daverman, Julian Eisner, Marvin Israel, R. C. Lacher, J. G. Hollingsworth, Martin Scharlemann, R. B. Sher, and DeWitt L. Sumners. The fourth special session, on Finite Groups, was organized by Professor Leonard J. Scott, Jr. of the University of Virginia and the participants were Professors Mark Benard, Arnold D. Feldman, Pamela A. Ferguson, Mark P. Hall, Jr., Peter Hoefsmit, Wayne R. Jones, Brian Parshall, and H. N. Ward.

There were also three sessions for contributed papers. These were chaired by Professors Don Hill, Allan G. Anderson, and J. R. Quine.

Professor Wendell Motter was in charge of local arrangements.

TAllahassee, Florida

O. G. HARROLD, JR. Associate Secretary

\title{
THE MARCH MEETING IN URBANA
}

The seven hundred thirty-third meeting of the American Mathematical Society was held at the University of Illinois at Urbana-Champaign from Monday, March 15 through Saturday, March 20, 1976. There were 377 registrants, including 273 members of the Society.

The period March 15-18 was devoted to a Symposium on Probability, which was supported by the National Science Foundation under a grant to the American Mathematical Society. The topic of the Symposium was selected by the 1974 Committee to Select Speakers for Western Sectional Meetings, which consisted of Richard A. Askey, Paul T. Bateman (chairman), and Donald J. Lewis. The Organizing Committee of the Symposium, responsible for selecting the speakers and arranging the program, consisted of Kai Lai Chung, Joseph L. Doob (chairman), Richard M. Dudley, Ronald K. Getoor, Frank B. Knight, and Frank L. Spitzer. The speakers at the Symposium were Donald L. Burkholder, Hans Föllmer, Jean Jacod, Naresh C. Jain, Harry Kesten, Frank B. Knight, Oscar E. Lanford III, Bernard Maisonneuve, Paul-André Meyer, P. Warwick Millar, Steven Orey, Mark A. Pinsky, Gilles Pisier, William E. Pruitt, Daniel Revuz, Daniel W. Stroock, John B. Walsh, Shinzo Watanabe, and David Williams.

By invitation of the Committee to Select Hour Speakers for Western Sectional Meetings there were three one-hour addresses. Professor Paul Erdös of the Hungarian Academy of Sciences addressed the Society Friday morning 
on the subject Probability methods in combinatorial analysis and number theory; he was introduced by Professor Irving Reiner. Professor Stephen Wainger of the University of Wisconsin and the Institute for Advanced Study gave an hour talk Friday afternoon on Some problems in harmonic analysis related to curves; Professor Lee A. Rubel presided at Professor Wainger's lecture. Professor Hugh L. Montgomery of the University of Michigan spoke Saturday morning on The large sieve for the mathematician in the street; he was introduced by Professor Harold G. Diamond.

By invitation of the same committee there were six special sessions of twenty-minute papers on Friday and Saturday. Jay R. Goldman of the University of Minnesota and the University of California at San Diego organized a special session on Enumerative Combinatorics; the speakers were George E. Andrews, Richard A. Askey, Adriano M. Garsia, Curtis Greene, Lawrence H. Harper, Albert Nijenhuis, David L. Reiner, David P. Roselle, Richard P. Stanley, William T. Tutte, Dennis E. White, Herbert S. Wilf, and Stanley G. Williamson. Rolf Jeltsch of the University of Kentucky organized a special session on Numerical Solutions of Ordinary Differential Equations; the speakers were David A. Archer, R. Leonard Brown, George D. Byrne, Frederic H. Chipman, Julio Cesar Diaz, Byron L. Ehle, Rolf Jeltsch, Paul S. Jensen, J. Douglas Lawson, Bengt Lindberg, Werner Liniger, Farouk M. Odeh, Victor L. Pereyra, Jerrold S. Rosenbaum, Robert D. Russell, R. Bruce Simpson, Robert D. Skeel, H. A. Watts, Daniel D. Warner, Daniel S. Watanabe, Mary Fanett Wheeler, Peter B. Worland, and R. V. M. Zahar. Andrew Lenard of Indiana University organized a special session on Inequalities in Mathematical Physics; the speakers were Richard S. Ellis, Richard A. Holley, Cornelius O. Horgan, Lawrence E. Payne, and Loren D. Pitt. Peter A. Loeb of the University of Illinois at Urbana-Champaign organized a special session on Potential Theory; the speakers were Thomas E. Armstrong, Maynard G. Arsove, Moses Glasner, Myron Goldstein, Kohur N. Gowrisankaran, Peter A. Loeb, John C. Taylor, and Bertram Walsh. Ralph E. Showalter of the University of Texas organized a special session on Partial Differential Equations of Sobolev Type; the speakers were Jerry L. Bona, John R. Cannon, Paul L. Davis, Richard E. Ewing, David W. Fox, John E. Lagnese, Howard A. Levine, V. R. Gopala Rao, William Rundell, Zeev Schuss, Lars B. Wahlbin, and Margaret C. Waid. David Slepian of Bell Telephone Laboratories and the University of Hawaii organized a two-part special session entitled Tutorial on Information Theory; Part I (Friday morning) was devoted to Probabilistic Theory and had as speakers Toby Berger, Robert G. Gallager, Jacob Wolfowitz, and Aaron D. Wyner; Part II (Friday afternoon) was devoted to Algebraic Coding Theory and had as speakers Edward F. Assmus, Jr., Ian F. Blake, James L. Massey, and Neil J. A. Sloane.

On Friday there were five sessions of contributed ten-minute papers. These were chaired by William Abikoff, Mahlon M. Day, Larry L. Dornhoff, Gerald J. Janusz, and William F. Stout. Of the 23 ten-minute papers listed in the program, two were withdrawn; two late papers were added to the program, so that 23 ten-minute papers were actually presented.

URBANA，ILLINOIS

Paul T. Bateman Associate Secretary 